\title{
Atuando nas crenças na formação de professores para a diversidade cultural
}

Geneva Gay ${ }^{1}$

\section{Resumo}

Essa discussão se concentra em um aspecto da formação de professores para a diversidade que é frequentemente mencionado, mas não suficientemente desenvolvido em detalhe. Trata-se das atitudes e das crenças de alunos e professores de pedagogia sobre as diferenças raciais, culturais e étnicas. Essas diferenças constituem os alicerces ideológicos das decisões e comportamentos didáticos e atendem aos critérios de estruturas profundas e metas de segunda ordem da reforma educacional desenvolvidos por Cuban.

Palavras-Chave: diversidade; questões de raça/ classe/ gênero; conhecimentos e crenças de professores.

1 Pesquisadora sobre educação multicultural e teoria do currículo geral.Professora da Universidade de Washington, Seattle, EUA. ggay@uw.edu 


\title{
Acting on Beliefs in Teacher Education for Cultural Diversity
}

\begin{abstract}
This discussion focuses on aspect of education for diversity that is frequently mentioned but not developed in sufficient detail. It is preservice teachers' and teacher educators' attitudes and beliefs about racial, cultural, and ethnic differences. These are the ideological anchors of teaching decisions and behaviors and meet Cuban's criteria of deep structures and second-order targets of educational reform.
\end{abstract}

Keywords: Diversity, race/class/gender issue, teacher knowledge and beliefs

\section{Introdução}

A diversidade étnica, racial, cultural, social linguística, que está crescendo vertiginosamente nas escolas norte americanas e na sociedade, é uma característica definidora de nossas vidas, mesmo se frequentemente tentamos negar sua existência ou minimizar sua importância no empreendimento educacional. Os professores precisam descobrir o sentido pessoal e pedagógico do que em alguns momentos parecem ser contradições incompreensíveis relacionadas à sociedade. Os cursos de Pedagogia precisam ajudar os professores a desenvolver as competências necessárias para confrontar e resolver esses dilemas. As mudanças necessárias deveriam ser o que Cuban (1988) chamou de segunda ordem, no que afetam as estruturas profundas e as suposições de valor subjacentes a todas as dimensões da formação dos professores e da prática em sala de aula. Pequenas mudanças não serão suficientes porque as orientações e ênfases eurocêntricas são mais inadequadas que nunca para estudantes de diferentes contextos culturais, raciais e étnicos. O curso de pedagogia ainda é dominado por estudantes e instrutores europeu-americanos, mas as crianças das 
escolas públicas são radicalmente diferentes, tanto em aspirações quanto em realidades. Estudantes cada vez mais diversos étnica e racialmente, suas famílias, comunidades e defensores estão exigindo o direito de serem reconhecidos, respeitados e instruídos pelo que eles são, em vez de terem que se adequar às normas eurocêntricas como condição para receber oportunidades educacionais de alta qualidade.

\section{O objetivo}

Mudanças nas orientações ideológicas e nas ações pragmáticas da formação dos educadores, necessárias para satisfazer essas demandas, exigirão um compromisso com a diversidade cultural em níveis de intensidade, profundidade e magnitude que excedem em muito qualquer coisa já feita. Muitos estudiosos da educação multicultural BANKS \& BANKS, 2004; COCHRAN-SMITH; DAVIS \& FRIES, 2004; GAY, 2000; GRANT; ELSBREE \&; FONFRIE, 2004; KING, HOLLINS \& HAYMAN, 1997; SLEETER, 2001; VILLEGAS \&; LUCAS, 2002) já sugeriram quais seriam essas prioridades. Contudo, algumas ainda precisam de refinamento e re-conceituação.Essa discussão tem seu foco em uma das prioridades, a qual é frequentemente mencionada, mas não suficientemente desenvolvida, que é interrogar as atitudes e crenças do currículo dos cursos de Pedagogia, dos estudantes e do professor, sobre a diversidade racial, cultural e étnica. As crenças dos professores têm profunda influência no seu julgamento educativo e nas suas ações (KNOPP; SMITH, 2005; PAJARES, 1992; SMYLIE, 1995). Smylie (1995) enfatiza a importância desta descoberta explicando que "a fim de mudar a prática de modo significativo e que valha a pena, os professores precisam não apenas aprender novos conteúdos e técnicas educativas, mas também modificar suas crenças e concepções de prática, suas teorias de prática e suas 'teorias de ação'” (p. 95).

Ao longo dos anos, muito foi escrito sobre as atitudes, percepções e crenças dos professores na ativa em relação aos estudantes de cor, como pesquisas conduzidas e resenhas citadas por Good e Brophy (2003), Raths e McAninch (2003), Banks e Banks (2004), Brown (2004) 
e Oakes (2005). Pesquisas sobre as crenças dos futuros professores em relação à diversidade racial, étnica e cultural não são tão antigas ou vastas, mas estão aumentando rapidamente. Estudos recentes conduzidos por Cochran-Smith (2000), Stuart e Thurlow (2000), Brown (2004), Brown (2004), e Case e Hemmings (2005) são ilustrações dessa tendência. A premissa básica deste estudo e a discussão aqui apresentada é que atitudes e crenças raciais, étnicas e culturais estão sempre presentes, são frequentemente problemáticas e profundamente significativas na moldagem das concepções e ações educativas. Mas frequentemente essas ações e crenças não são claramente articuladas e cuidadosamente examinadas nos cursos de Pedagogia. No decorrer desta discussão, atitudes e crenças problemáticas sobre varias dimensões da diversidade cultural são identificadas; explicações sobre como elas são manifestadas entre estudantes de Pedagogia são apresentadas; seus efeitos e consequências são propostos; e algumas sugestões são dadas para o desenvolvimento de atitudes e ações mais positivas em relação à diversidade cultural no ensino. As evidências que suportam essas ideias, explicações e recomendações derivam de pesquisas anteriores e meus próprios anos de experiência como formadora de professores multiculturais.

\section{Atitudes, crenças e a barreira cultural}

A sub-representação de africanos, asiáticos, latino-americanos e índios norte-americanos nos cursos de Pedagogia, entre formadores de professores, assim como na sua distribuição demográfica nas escolas de Educação Básica ${ }^{1}$, já é suficientemente familiar, não exigindo maiores elaborações nessa ocasião (COCHRAN-SMITH, 2004; KOZOL, 2005; MEIER; WOOD, 2004; VILLEGAS; LUCAS, 2002). As mensagens e atitudes ocultas nesses dados demográficos têm profundas consequências para o ensino e a aprendizagem, mas não são tão familiares e nem frequentemente discutidas. Uma dessas consequências é o fato de que a maioria dos alunos culturalmente diversos e seus professores vivem em mundos diferentes e não compreendem inteiramente ou não 
apreciam a realidade experiencial um do outro. As interações diárias entre eles são esporádicas e superficiais e seu conhecimento sobre a diversidade cultural é largamente filtrado pela mídia de massa. Esse tipo de contato e essas informações relacionadas estão longe do desejável e frequentemente produzem percepções distorcidas de uns a respeito dos outros, crenças infundadas e atitudes preconceituosas em relação a indivíduos, grupos e culturas étnica e racialmente diversos. Como assinalado por Nieto (2005),

Não é surpreendente que alguns professores tenham percepções negativas, preconceitos e atitudes racistas sobre os alunos a quem eles ensinam, e sobre suas famílias, culturas e comunidades... Professores... captam as mesmas mensagens e têm as mesmas concepções erradas de todos nós, é apenas confrontando aquelas que atrapalham o aprendizado do aluno que a mudança poderá ocorrer. Isso significa encorajar os professores, futuros e atuais, a refletir profundamente sobre suas crenças e atitudes... [e fornecer] a eles os recursos e o suporte necessários para que eles possam realizar este trabalho que é difícil, mas empoderador a longo prazo. (p. 217-218)

Ayers (1992) apresentou uma mensagem igualmente persuasiva. Ele disse: "Nós somos, cada um de nós, fundados em um contexto, incorporados em um mundo físico, cultural, que não criamos" (p. 155). Em outra publicação, Ayers (2004) acrescentou que todos somos "nascidos em uma raça e um lugar, e todas as primeiras lições são para conhecer algo de cada um desses" (p. 66). Ainda que "raça seja tabu" (p. 65), porque frequentemente esforços e oportunidades para submeter as crenças e os comportamentos raciais a cuidadoso escrutínio são abandonados por conforto, harmonia e coleguismo ilusórios. Desse modo, "ficamos sem palavras" (p. 66) nos discursos pedagógicos. Mas professores e alunos não precisam ficar mudos, eles podem (e devem) aprender a expressar seus pensamentos e crenças sobre raça, etnia e diversidade cultural e sobre como reconstruí-las ou transformá-las.

Muito tem sido dito em diversos fóruns, sobre diferenças culturais e distâncias contextuais entre professores de classes euro-americanas e alunos de cor, mas os formadores de professores também têm pouco contato e conhecimento de grupos, culturas e experiências culturalmente 
diversos. Professores e pessoas de cor têm crenças errôneas e "percepções distorcidas sobre", bem como "interações limitadas com", euroamericanos e uns com os outros, tanto no interior de um grupo quanto entre grupos étnicos. Desse modo, afro-americanos podem "não saber muito sobre" ou "não ter interagido diretamente com" afro-caribenhos e imigrantes recentes de vários países africanos, ou com asiáticoamericanos, latino-americanos, ou indígenas americanos. Professores e alunos de ascendência japonesa podem ter preconceitos profundamente enraizados contra e concepções erradas de alunos de ascendência coreana, vietnamita, chinesa e filipina e assim por diante. Quando essas atitudes e crenças distorcidas são apresentadas na sala de aula (como invariavelmente são), elas "interferem no" mais do que "facilitam o" ensino e a aprendizagem. Os cursos de Pedagogia precisam fazer um trabalho melhor do que estão fazendo para ajudar seus estudantes a examinar as causas e a natureza das diferentes atitudes e crenças que eles têm a respeito de certos grupos e culturas étnicas.

Em que os futuros professores acreditam quanto às causas fundamentais das diferenças entre seus alunos etnicamente diversos, e entre eles mesmos e seus alunos? Será que eles examinam criticamente essas questões em algum momento? Será que eles desejam e são capazes de articular suas atitudes e crenças sobre a diversidade cultural, ou ainda, de mudar suas atitudes e crenças para produzir outras mais positivas? Será que eles conseguem reconhecer certas crenças implícitas em algumas decisões e comportamentos didáticos? Entre os futuros professores, quais possuem quais crenças sobre quais grupos específicos de cor e por que pensam assim? Essas são questões difíceis, mas importantes, que deveriam ocupar grande parte da formação de professores nesta era de diversificação em massa dos estudantes dos Ensinos Fundamental e Médio, muitos dos quais têm necessidade urgente de intervenções radicalmente diferentes para melhorar suas oportunidades educacionais e seu rendimento escolar. Esse processo de mudança deve começar na preparação profissional dos professores, expondo-os a uma análise crítica de suas atitudes e crenças sobre a diversidade cultural em geral e no contexto escolar. Eles também deveriam ser guiados na prática 
de adotar novas crenças que são mais compatíveis com a aceitação e a promoção da diversidade cultural no currículo e no ensino das escolas de ensino fundamental e médio. Por exemplo, como os futuros e atuais professores podem ser ajudados a superar a crença de que alunos pobres e de cor, e suas famílias, não valorizam a educação, para aceitar que eles possam expressar suas crenças educacionais de modos diferentes daqueles que são familiares para a classe média, para os professores usuais e que são frequentemente incompreendidos por eles? Como as atitudes e comportamentos didáticos mudariam se se enfatizassem o talento, o potencial e as forças dos alunos, famílias e comunidades de culturas diferentes, em vez dos seus problemas e patologias?

\section{Crenças sobre o engajamento da diversidade cultural}

Poucos dos futuros professores pensam profundamente sobre suas atitudes e crenças a respeito da diversidade étnica, cultural e racial; alguns até resistem deliberadamente a fazê-lo. Quando meus alunos são questionados sobre isso, eles afirmam ser "além da raça, etnia e cultura", não enxergar cores, ou defender a sociedade sem raças. Mas eles não conseguem articular, com qualquer profundidade de pensamento, o que essas ideologias significam, porque eles a seguem, e como se traduzem em comportamentos didáticos. Eles tendem a lançar mão de chavões como "É a coisa certa a fazer porque raça, cultura e etnia não interessam" e "pessoas são pessoas, e nós devemos lidar com elas como indivíduos". Eles não pensaram muito sobre como a divisão cultural que existe entre eles mesmos como professores e seus alunos afeta o acesso e a qualidade das oportunidades de aprendizagem para os indivíduos de grupos étnicos diferentes. Eles rejeitam a necessidade de uma análise mais profunda das diferenças com ideias como "nenhum racismo intencional está envolvido" ou "nem todos os estudantes podem aprender as mesmas coisas, então as disparidades refletem mais as habilidades individuais do que injustiças sistêmicas". Alunos de Pedagogia justificam esse pensamento porque eles não querem ser acusados de ser racistas ou de dizer coisas erradas. A ideia tácita, mas claramente expressa, é que "falar 
sobre diferenças, especialmente aquelas relacionadas a raça, é um tabu". Partes do problema aqui são a falta de experiência com pessoas que são diferentes, uma confusão conceitual entre reconhecer as diferenças e discriminar o aluno de cor e a suposição falaciosa de que conversar sobre raça com pessoas de cor será sempre contencioso.

Também não é útil para a construção de relações genuínas, de confiança e colaborativas com colegas de culturas e etnias diversas, que o professorado euro-americano do curso de Pedagogia e seus alunos iniciem esses esforços com declarações sobre quão difícil e incômodo é para eles falar a respeito de raça, sobre seu desejo de "lugares seguros" e "zonas de conforto" para que essas conversas ocorram, ou que eles ensinariam diversidade cultural, se ao menos soubessem como. Não é positivo para as pessoas de cor serem consideradas medrosas, e é inconcebível para pessoas que foram vítimas do racismo que esforços genuínos para resistir a ele e eliminá-lo (bem como outras formas de opressão) não possam avançar enquanto ambientes de segurança, certeza e conforto não forem construídos. Nem são eles muito compreensivos para com colegas envolvidos em ensinar a outros como aprender quem não deseja aplicar as mesmas habilidades a si mesmo para preencher o seu vazio cognitivo e pedagógico sobre a diversidade cultural.

Uma observação feita por Cochran-Smith (2004) é oportuna aqui. Ela diz que:

Como formadores de professores não podemos evitar conversas desagradáveis e duvidosas, porque o fracasso ou receio em olhar, ouvir e aprender sobre a diversidade, a opressão e as experiências das outras culturas interfere significativamente na habilidade de criticar e problematizar a educação ou "ensinar contra as crenças comuns". (p. xii)

Howard (2006) esboça um objetivo ainda mais persuasivo e faz uma previsão desafiadora. Falando como um educador multicultural branco para educadores brancos, ele advertiu que:

Não podemos nos engajar completamente e frutiferamente em um diálogo significativo através das diferenças de raça e cultura sem fazer o trabalho da transformação pessoal... Nós não podemos ajudar nossos alunos a superar as repercussões negativas da dominância passada e presente do racismo se não tivermos 
compreendido os remanescentes dessa dominância na nossa cabeça, no coração e nos hábitos... Não haverá nenhum movimento significativo em direção à justiça social e à reforma educacional real enquanto não houver uma transformação significativa nas crenças, atitudes e ações dos americanos brancos. (p. 6)

Nieto (2005) identificou cinco atitudes que ela considera essenciais para que os professores sejam promotores efetivos da diversidade cultural e justiça social, são elas: a) senso de missão de servir crianças etnicamente diversas para potencializar suas habilidades; b) solidariedade com, empatia por e valorização da vida, das experiências, da cultura e da dignidade humana dos alunos; c) coragem para questionar os pressupostos normais de conhecimento na escola e as maneiras convencionais de atuar e as crenças e suposições sobre alunos, famílias, culturas e comunidades diversas; d) disposição para improvisar, inovar, ir além dos moldes e estruturas estabelecidos e para abraçar a incerteza e a flexibilidade; e) a paixão pela igualdade e justiça social. Cultivar essas atitudes pode constituir o âmago dos programas de formação de professores, voltados para desenvolver crenças que são as bases ideológicas para incorporar a diversidade cultural no comportamento educativo.

Indivíduos de variados contextos étnicos têm crenças diferentes e formas de se aproximar da diversidade étnica, racial e cultural como conteúdo do currículo, das técnicas educativas e do relacionamento com os alunos. Isso é verdade para professores e alunos de Pedagogia e crianças dos Ensinos Fundamental e Médio. Em minha experiência como professora, observei que os estudantes de cor tendem a falar de maneira mais franca e com mais detalhes sobre a diversidade de raça, etnia e cultura do que os euro-americanos. Os afro-americanos são mais vigorosos, apaixonados e pessoais no estilo de se expressar; os asiático-americanos são mais indiretos, sutis e confrontam menos; os euro-americanos tendem a ser mais evasivos e silenciosos. Mesmo que possa não ser fácil fazê-lo, atuais e futuros professores de cor reconhecem a necessidade de ter conversas direta e especificamente focadas na diversidade cultural, em vez de falar indiretamente sobre o assunto. Se ignoradas, essas diferentes formas de interagir podem causar profundos desentendimentos e impedir esforços igualitários e 
colaborativos entre professores e alunos das maiorias e minorias para melhorar o aprendizado de todos.

Formadores de professores e professores precisam acreditar e agir em conformidade com o fato de que os problemas relacionados ao ensino para, na e por meio da diversidade cultural não podem ser solucionados enquanto não forem reconhecidos e confrontados, suas causas e características compreendidas, e não forem desenvolvidas estratégias deliberadas para sua resolução. Eles também precisam entender que o que eles consideram problemático sobre certas manifestações da diversidade cultural pode ser natural e normal para os membros de outros grupos étnicos e comunidades profissionais. Trent, Kea e Oh (2008) nos lembraram que "o que não é reconhecido por fim se torna invisível" (p. 346). Estudiosos da educação multicultural há muito propõem o uso de múltiplas perspectivas étnicas como uma estratégia educacional que pode ser aplicada por professores de pedagogia nesses tipos de situações de aprendizagem.

Idealmente, no processo educativo, a diversidade cultural seria aceita como um atributo positivo e um recurso valioso para o ensino e a aprendizagem. Na realidade, é frequentemente vista como uma ameaça e um prejuízo a ser negado, evitado, ou eliminado. Muitos atuais e futuros professores ficam incomodados com as aparentes contradições entre esses ideais e a realidade e têm dificuldade em encontrar um lugar ideológico confortável para eles mesmos nesse conflito. Eles respondem tentando encontrar consolo no silêncio, na negação e na alienação social, enfatizando aspectos da diversidade (como gênero, classe social e individualidade) que não são tão incômodos para eles, isentando-se de qualquer responsabilidade pessoal por causar e corrigir opressões e injustiças e enfocando o que deveria ser em vez do que é. Case e Hemmings (2005) constataram que este era o caso, em seu estudo sobre as atitudes de futuras professoras brancas em relação ao currículo e a conversas sobre injustiças sociais. O mesmo constataram Sleeter (2001), Trent et al. (2008), e Walker-Dalhouse e Dalhouse (2006) em seus artigos de pesquisas a respeito das crenças e conhecimentos dos alunos de pedagogia sobre a opressão, as culturas, 
as experiências e contribuições de grupos de cor etnicamente diversos e sobre ensinar alunos que são membros desses grupos. Alguns dos meus alunos da Pedagogia acreditam que pessoas de cor são sensíveis demais e exageram os efeitos prolongados e a intensidade do racismo, da discriminação e das oportunidades educativas de baixa qualidade. Outros argumentam que a sociedade dos Estados Unidos está agora numa era pós-racial e que concentrar em diversidade cultural e injustiças sociais na Educação não é mais necessário. Trent et al. (2008) chamou essas reações de "estratégias de distanciamento" (p. 333). Mesmo que examinar crenças sobre raça, racismo, etnia e cultura possa ser de fato desafiador, é necessário. E não precisa ser com métodos inteiramente novos, idiossincráticos ou experimentais. Pesquisas em Educação Multicultural, Ciências Sociais e Humanidades fornecem orientações úteis. Conhecimentos e técnicas compilados da sociolinguística podem ajudar os professores a comunicar suas ideias, pensamentos e crenças sobre a diversidade cultural de forma mais clara e convincente. Se os futuros professores não souberem desses recursos, eles podem concluir que raça, etnia e cultura não podem ser compreendidas com nenhum grau de consenso ou segurança. $\mathrm{Ou}$, talvez, eles concluam que podem definir essas questões e conceitos de acordo com seu próprio critério sem serem informados pelos conhecimentos e pensamentos disponíveis de especialistas. As duas opções deixam os professores sem parâmetros ideológicos bem fundamentados para guiar seus pensamentos e ações e podem produzir estratégias educativas atoladas na confusão e na ambiguidade. Como digo frequentemente a meus alunos: "Assim como você não presumiria acreditar que pode definir a leitura, a Matemática ou a Ciência sozinho, da mesma maneira não pode fazê-lo com relação a Educação Multicultural; pesquisas disciplinares existem para fazer isto. Além disso, a simetria total de estilos expressivos e uso da linguagem entre os estudiosos não é necessariamente para que exista um consenso de ideias e significados. Estudiosos podem concordar sobre componentes e atributos essenciais de raça, etnia, cultura e educação multicultural sem ter que falar com uma só voz. É insensato esperar qualquer coisa diferente de estudiosos de qualquer área de estudo, e especialmente 
estudiosos voltados a promover a diversidade cultural."

Algumas questões relacionadas ao tema e que deveriam ser exploradas pelos futuros professores são "O que faz com que uma pessoa acredite que diferentes profissionais deveriam ter crenças idênticas sobre etnia e diversidade cultural e expressá-las de modo idêntico? Por que essa expectativa é colocada na educação multicultural, mas não nas outras áreas de estudo como a História, Antropologia, Humanas, Artes e Ciências? Como podem os leitores dos textos de Educação Multicultural discernir o consenso do significado no meio da diversidade de estilos de linguagem e escrita? Quais as semelhanças entre aceitar a diversidade de estilos de escrita entre estudiosos da Educação Multicultural, desenvolver habilidades para ler além da forma para achar substância, e ensinar alunos culturalmente diversos? Como pode a diversidade nos dois contextos (ler textos multiculturais e ensinar em classes culturalmente diversas) ser um recurso para o enriquecimento pessoal e o sucesso educativo?"

Aprender como ler pesquisas sobre diversidade cultural deve ser destacado no currículo do curso de Pedagogia, especialmente aquelas pesquisas produzidas por estudiosos de cor que deliberadamente embutiram nuances culturais e marcadores na sua escrita, como cada vez mais pesquisadores tem feito. Se isso não for feito, os futuros professores podem desenvolver atitudes negativas em relação a pesquisas culturalmente diversas e chegar a conclusões errôneas sobre a credibilidade, competência e domínio dos autores. Eles podem duvidar se suas ideias e análises devem ser seriamente consideradas, uma vez que "não escrevem como os estudiosos deveriam". Eles também podem perder algumas informações vitais para construir conhecimentos necessários e fundamentos pedagógicos para o ensino da diversidade cultural.

Eu forneço aos meus alunos oportunidades de analisar diferentes tipos de pesquisas de Educação Multicultural para fundamentar princípios embutidos em textos narrativos, orientações disciplinares do autor e crenças, referências e notações culturais implícitas. Antes de os alunos iniciarem essa análise, eu explico alguns atributos frequentemente utilizados por autores afro-americanos educacionais e literários que escrevem com uma voz cultural autêntica. Em seguida, os alunos leem 
argumentos cultos a favor do uso da diversidade linguística em vários cenários de comunicação e ensino e examinam amostras de textos acadêmicos e literários para ver como esses atributos culturais aparecem na prática atual. Os alunos também analisam uma seleção de livros infantis de imagens escritos por autores afro-americanos, para ver se eles conseguem identificar alguns dos traços culturais especificados no texto escrito e nas ilustrações. Eles examinam criticamente seus próprios sentimentos e crenças sobre a validade ou viabilidade de usar esses textos culturais em sala de aula com afro-americanos, bem como com alunos de outros contextos étnicos.

Essas análises reflexivas das atitudes e crenças associadas a textos culturais são coerentes com a importância e o potencial do autoestudo no desenvolvimento profissional de professores (COCHRAN-SMITH, 2000; LOUGHRAN et al. 2004; LOUGHRAN; RUSSELL, 2002; SCHUBERT; AYERS, 1992; SMART; THURLOW, 2000). Após repetidos esforços, os alunos começam a perceber que invariavelmente as crenças pessoais estão embutidas no pensamento analítico, na pesquisa empírica e nas práticas de ensino. Os conhecimentos ganhos são fundamentos úteis para entender porque alunos e professores culturalmente diversos respondem de maneiras diferentes uns aos outros e às experiências de aprendizagem, assim como a necessidade de se utilizar muitos tipos de estratégias educacionais culturalmente responsivas. Esses conhecimentos são uma valiosa fundamentação para que os futuros professores se tornem "profissionais conscientes" que "monitoram continuamente suas suposições básicas sobre ensino e aprendizagem [...] e sintonizam cuidadosamente os modos como suas suposições guiam e são criadas pela prática" (SCHUBERT; AYERS, 1992, p. ix).

Cochran-Smith (2000) identificou outro benefício importante do autoestudo, para que futuros professores se tornem criticamente conscientes de suas próprias atitudes e crenças sobre raça, etnia, racismo e diversidade cultural. A autora notou que utilizar narrativas para "se tornar pessoal" sobre essas questões pode revelar muitas experiências, nuances e complexidades necessárias para entender suas causas, manifestações e consequências. Cochran-Smith também descreve técnicas 
educativas, advindas de sua experiência como formadora de professores para a diversidade cultural e justiça social, que vale a pena investigar; estas incluem: aprender como identificar e interrogar suposições básicas implícitas no currículo, na pesquisa, nas bolsas de estudo do curso de Pedagogia e na Pedagogia como textos culturais, raciais e sociais.

\section{Entendendo como as crenças afetam os comportamentos didáticos}

Outra necessidade significativa na preparação de professores para a diversidade cultural é entender como as crenças sobre raça, classe, cultura, etnia e experiência afetam comportamentos didáticos. Uma área irá bastar para ilustrar essas profundas influências. Esta é o uso de exemplos para dar um significado funcional e relevância pessoal a conhecimentos abstratos, conceitos e habilidades no ensino. Os exemplos consomem uma porção significativa do tempo de ensino, independentemente do assunto ensinado, nível de escolaridade, tipo de estratégia de ensino utilizada, ou público de alunos. Eles são para os alunos a ponte significante entre as abstrações acadêmicas e suas realidades experienciais. Para os formadores de professores, o desafio é ajudar seus alunos a entender suas crenças sobre o que constituem exemplos educacionais valiosos e como multiculturalizá-los.

A maioria dos futuros professores não tem consciência do poder e proeminência dos exemplos no ensino. Eles tendem a equiparar exemplos e ilustrações instrutivas com o currículo formal e materiais escritos e ignorar os exemplos pessoais informais. Eles não se dão conta de que algumas crenças muito fortes sobre a diversidade cultural podem ser expressas por meio dos exemplos habitualmente utilizados no ensino. Isso pode ser tanto positivo quanto negativo. Por exemplo, mensagens negativas e crenças implicitamente preconceituosas são transmitidas por meio das referências habituais à pobreza e ao alcoolismo relacionados a indígenas americanos contemporâneos e crime, violência e "famílias divididas" quando discutindo afro-americanos. Contrariamente, crenças e mensagens positivas são expressas ressaltando as conquistas estelares 
dos asiático-americanos. Exemplos menos óbvios que podem transmitir crenças negativas sobre pessoas culturalmente diversas incluem sempre posicioná-las no papel de vítimas e dependentes, ou ignorar sua presença de todas as maneiras. Esses comportamentos são baseados na crença de que certos grupos étnicos são insignificantes no empenho em algumas áreas, enquanto outros são proeminentes. Para ilustrar com algumas perguntas: por que "o Renascimento" ainda é concebido e ensinado como um fenômeno apenas do leste europeu, largamente masculino? Não seria mais preciso e respeitoso à diversidade cultural ensinar que diferentes culturas têm seus renascimentos que são tão significativos quanto "O" Renascimento nos seus próprios contextos? Por que os professores usam exemplos de sua experiência pessoal como recursos de ensino e aprendizagem válidos, mas negam a mesma prerrogativa aos seus alunos étnica e culturalmente diversos?

Cursos de pedagogia e seus professores deveriam ensinar futuros professores a como ficarem conscientes dos seus hábitos de utilizar exemplos e como modificá-los para que sejam culturalmente mais diversos. Analisar gravações em vídeo das práticas de formadores de professores, os comportamentos de aprendizagem de futuros professores e amostras de professores em prática na sala de aula para identificar padrões e tendências no uso de exemplos, e extrair as crenças implícitas neles, pode ser uma estratégia útil de transformação. Outras formas de desenvolver essas habilidades exigem que os futuros professores a) analisem seus próprios hábitos e os dos outros de fazer referência a exemplos étnica e culturalmente diversos em várias situações de ensino; b) desenvolvam protocolos descritivos que caracterizem diferentes tipos de exemplos que eles e outros utilizam e os repliquem em diferentes experiências étnicas; c) criem ou colecionem exemplos de ensino de diferentes orientações étnicas, diferentes daqueles normalmente usados em sala de aula; e d) usem habitualmente múltiplos exemplos culturalmente diversos para ilustrar conceitos, conhecimentos e habilidades de ensino.

Aplicando essas estratégias de aprendizagem, minhas turmas examinam por que e como os processos de dar tarefas para casa são próximos dos hábitos profissionais da classe média e especulam sobre como esse aspecto 
importante do ensino e aprendizagem pode ser modificado para melhor se adequar aos estilos de trabalho das pessoas mais pobres. Eles também deixaram de usar modelos de conduta tradicionais de diferentes grupos étnicos, tipicamente ensinados nas salas de aula dos Ensinos Fundamental e Médio (como Martin Luther King Jr. e Rosa Parks para afro-americanos, e Cesar Chavez para os mexicano-americanos) e os substituíram por algumas celebridades novas e desconhecidas, incluindo mulheres contemporâneas que lutam pela justiça social que não são europeias ou afro-americanas. Esses exercícios alargam as bases de conhecimento pessoal dos futuros professores e os ajudam a confrontar suas crenças sobre heroísmo e excepcionalidade, a reconhecer que diferentes grupos étnicos têm seus próprios critérios e parâmetros culturais sobre o sucesso, a criar recursos e modelos valiosos de ensino para utilizar com seus próprios alunos e a dar significado prático para a ideia de mudar os comportamentos didáticos para refletir crenças e atitudes mais positivas sobre a diversidade cultural, étnica e racial.

\section{Outras possibilidades promissoras}

Algumas das minhas últimas turmas deram outros passos reveladores quanto a confrontar suas crenças sobre a diversidade cultural. Um grupo de alunos predominantemente euro-americanos matriculados em uma turma de Ensino Multicultural Básico foi convidado a pensar sobre e a articular suas próprias heranças culturais. Eu precisei encontrar uma forma que não fosse ameaçadora de facilitar essa exploração e de mover os alunos além da crença de que eles não tinham raça, cultura ou etnia, de que eram apenas indivíduos. Esforços anteriores de colocar os alunos para conversar publicamente sobre quem eles eram étnica e culturalmente não tinham obtido sucesso. As respostas mais comuns tinham sido a negação, o silêncio e a confusão. Para atravessar essas barreiras, eu introduzi a escrita de poesias metafóricas como um gênero alternativo de expressão. Os poemas deveriam ter quatro estrofes e cada uma dedicada às origens ancestrais dos grupos étnicos dos alunos, ao seu contexto familiar, aos seus atributos pessoais, e ao tipo de professor 
em defesa da diversidade cultural que eles gostariam de se tornar. Os alunos responderam muito favoravelmente à técnica e tarefa substanciais. Esta foi uma reação curiosa e, de certo modo, inesperada, uma vez que muitos já haviam declarado que não conseguiam escrever poesia.

Alunos de outra turma utilizaram uma variação dessa atribuição. Foi solicitado a eles que participassem em três estágios interligados de engajamento autorreflexivo com conceitos de raça, etnia, cultura e individualidade. No primeiro estágio, foi solicitado aos alunos que escrevessem um texto livre sobre suas percepções pessoais e entendimentos desses conceitos em geral. No segundo estágio, eles deveriam escrever um poema dialógico de sua própria etnia, cultura e individualidade. O diálogo deveria ser entre suas próprias percepções e as de outras pessoas significativas em sua vida, como um amigo, parente, cônjuge, irmão ou professor, que funcionaria como um "espelho humano" para os alunos. Os dois conjuntos de percepções deveriam ser apresentados como um diálogo dentro do poema. A terceira fase dessa atividade tinha duas partes: a) a turma, como um todo, identificou uma lista de oito a dez itens que eles consideravam essenciais para explorar e transmitir identidades étnicas, culturais e individuais; e b) os alunos criaram pôsteres individuais de mídia mista simbolizando esses itens consensuais da maneira como eles se aplicavam a eles mesmos. O projeto culminou em um passeio na galeria, com todos os pôsteres em exibição e os autores disponíveis para explicar e responder perguntas sobre o conteúdo do seu pôster, como e por que eles foram construídos daquela forma e as implicações daquela experiência de aprendizado para ensinar alunos cultural e etnicamente diversos nas turmas dos ensinos Fundamental e Médio.

Em uma terceira turma, foi dito aos alunos que o conteúdo do conhecimento de multiculturalidade e as habilidades pedagógicas se desenvolviam ao longo do tempo, que seu domínio é análogo a fazer uma jornada. Foi pedido aos alunos que fizessem uma mala metafórica com as coisas que eles levariam na sua jornada em direção à competência multicultural. Poderia ser qualquer coisa (incluindo atitudes, crenças, valores, experiências, memórias, ambiguidades, incertezas, ansiedades, 
epifanias, socializações anteriores, heranças, perguntas, "lista de desejos") que eles achassem que poderia facilitar ou interferir no sucesso da sua jornada - ou seja, captar o sentido e desenvolver habilidades para o ensino multicultural. Essa atividade pretendia ser uma forma sutil e não ameaçadora de os alunos se engajarem no autoestudo sobre sua cultura e etnia; reconhecerem que os euro-americanos têm uma raça, cultura e etnia; tornarem-se conscientes dos "quês", "porquês" e "comos" da sua própria identidade cultural e heranças, bem como dos outros; e perceberem que influências culturais estão sempre presentes nas crenças, atitudes, valores e comportamentos das pessoas.

Nessas atividades de aprendizagem, poesia e metáfora foram escolhidas como meios de expressão por causa do pensamento altamente crítico e abstrato que as fundamenta e porque eu acreditava que seu uso poderia encorajar os alunos a aprofundarem nas reflexões pessoais sobre e na análise intelectual da raça, cultura e etnia, mais do que fazendo descrições narrativas ou redações explicativas. Os alunos se expressaram de maneira muito mais livre sobre suas etnias e heranças culturais e relataram que se sentiram validados, empoderados e agradecidos pela oportunidade de "se expressarem". Eles rapidamente reconheceram como atividades similares podem ser usadas com os alunos dos ensinos Fundamental e Médio e produzir sentimentos de ser dono da própria vida, ser eficaz e empoderado. Uma vez que os meus alunos começaram a se compreender como seres culturais, eles ficaram mais receptivos a aceitar a cultura, raça e etnia dos alunos a quem eles irão, por sua vez, finalmente ensinar. Ademais, eles não foram tão insistentes em afirmar que no bom ensino "é apenas a individualidade do aluno que conta", sem problematizar essa banalidade. Uma mensagem pedagógica importante advinda dessas experiências de aprendizado é que futuros professores precisam da prática guiada dentro de parâmetros bem estabelecidos para ajudá-los a nomear e analisar suas crenças sobre etnia e diversidade cultural.

A uma quarta turma foi dada a tarefa de escrever credos pedagógicos pessoais culturalmente receptivos. Eles deveriam ser escritos de modo a mostrar os corolários de crenças e comportamentos e atender às várias dimensões da educação multicultural que os alunos vinham estudando. 
Se os credos declarados atendessem aos critérios esperados, a primeira parte de lidar com as crenças seria uma reflexão geral sobre os aspectos da ideologia multicultural que ressoava com os alunos e a segunda parte seriam ações de ensino bem específicas que os alunos imaginavam para eles. O ponto de partida dessas sugestões foi "Eu acredito que..., então eu vou... ." Uma amostra completa poderia ser "Eu acredito que a diversidade cultural deveria ser incorporada aos conhecimentos considerados e às habilidades de grande importância e grande impacto ensinadas nas escolas; por isso eu vou usar estatísticas de distribuição populacional para ensinar habilidades matemáticas como porcentagem, proporção e probabilidade."

Essa atividade de aprendizagem tinha a intenção de fornecer uma oportunidade aos futuros professores de articular suas crenças sobre o ensino da diversidade cultural, de começar o processo de traduzir crenças gerais em comportamentos didáticos específicos, de ver que as crenças e os comportamentos estão interconectados e de dar significado prático à ideia teórica de incorporar a diversidade cultural a outras áreas do ensino e da aprendizagem. O projeto não atingiu o sucesso que eu esperava. Alguns alunos tiveram êxito em declarar crenças, mas tiveram dificuldade em especificar adequadamente comportamentos relacionados. O que alguns identificaram como suas crenças eram na verdade declarações selecionadas dos textos de vários estudiosos da educação multicultural, em vez de crenças pessoais internalizadas. Apesar do seu sucesso limitado, o projeto serviu de treinamento valioso para os alunos e para mim. Reafirmou a dificuldade dos atuais e futuros professores de esclarecer suas crenças sobre a diversidade cultural e traduzi-las em comportamentos educacionais, levantou questões sobre a profundidade das suas crenças e comprometimentos subjacentes e revelou a necessidade de eles terem mais oportunidades e assistência na prática desses esforços.

Experiências de aprendizagem como essas são úteis para fazer com que futuros professores comecem a se questionar sobre suas crenças raciais, étnicas e culturais e a se compreender como pessoa e profissional. De qualquer forma, é preciso cuidado para que o foco em si próprio não 
ofusque compreender e responder a diversidade cultural, étnica e racial das crianças e adolescentes a quem vão ensinar. Outro perigo potencial com os alunos da maioria cultural é que experiências de aprendizagem de "se conhecer melhor" podem reafirmar seu senso de privilégio e direito, enquanto os futuros professores de cor podem considerá-las invasivas e muito reveladoras. Quanto a esse último ponto, CochranSmith (2000) advertiu aos formadores de professores ficarem atentos para não usar a dor e a luta de grupos de cor para reforçar o entendimento de raça, cultura e etnia dos grupos privilegiados da maioria, vez de serem compreendidos no seu próprio contexto. Isso pode ser evitado fazendo com que todos os alunos examinem essas questões a partir de sua própria perspectiva, assim como pela perspectiva de outros, analisando recursos de estudiosos além do seu autoestudo e todos aprendendo sobre o ensino com total atenção para as diferenças de raça, cultura e etnia, não independentemente delas. Outras ressalvas: alguns futuros professores podem achar que "consciência" é preparação suficiente para ensinar sobre a diversidade cultural e para alunos etnicamente diversos sem modificar suas políticas, seus programas e suas práticas. Eles podem ficar com a impressão de que lidar com o racismo institucional enraizado, impotência, injustiça e ativismo transformador não é tão importante no final.

Armadilhas potenciais como estas podem ser evitadas explicitando para os futuros professores que analisar criticamente suas crenças e se conscientizar de sua própria herança cultural são apenas dois de muitos componentes da preparação para ensinar para e por meio da diversidade cultural. Outras questões de igual importância são desenvolver conhecimentos básicos sobre as heranças culturais específicas e contribuições de diferentes grupos étnicos, desenhar cursos e matérias que levem em conta a diversidade cultural para diferentes grupos étnicos, criar um ambiente culturalmente inclusivo nas salas de aula e nas comunidades de aprendizagem, utilizar procedimentos e técnicas multiculturais para avaliar o desempenho dos alunos, incluir competências multiculturais entre os critérios dos rendimentos esperados e estabelecer relacionamentos cuidadosos e construtivos com alunos de diversas etnias, culturas, raças e línguas. 


\section{Desafios atuais}

Um progresso notável já foi feito na formação de professores para a diversidade étnica e cultural desde que a Associação Americana de Faculdades de Educação publicou sua política de 1973 "Sem um único modelo de americano", e o Conselho Nacional para a Certificação de Pedagogia incluiu educação multicultural entre seus critérios de certificação em 1978. Mas o progresso está longe do ideal, e necessidades significativas ainda não foram adequadamente abordadas. A natureza desse progresso e essas necessidades são similares nos cursos de Pedagogia por todo os Estados Unidos, de acordo com várias pesquisas recentes e revisões da literatura (BANKS; BANKS, 2004; COCHRANSMITH et al., 2004; GRANT et al., 2004; SLEETER, 2001; TRENT et al.,2008). Elas revelam que cada vez mais cursos de Pedagogia estão incluindo algo de diversidade cultural como conteúdo integrado nos seus currículos e como cursos independentes de educação multicultural. O conteúdo enfatiza ideologias sobre a diversidade cultural, desenho de currículos e competências pedagógicas multiculturais, assim como efeitos da diversidade cultural no ensino e aprendizagem. Outras pesquisas sobre práticas na formação de professores chegaram a resultados similares, como antologias compiladas por King et al. (1997), Larkin e Sleeter (1995), Banks e Banks (2007) e Miller (2009).

Embora o auge da resistência em incluir diversidade cultural na formação de professores já tenha passado, as formas de lidar com a inclusão de fato não são tão bem-sucedidas quanto necessário. Geralmente, trata-se de conduzir os alunos de alegações de desconsiderar a cor para uma consciência cultural; pedagogicamente, evoluir de conhecimento das diferenças culturais para ações educativas que levam em conta a cultura; moralmente, evoluir da tolerância para a promoção da diversidade cultural e étnica; e, politicamente, evoluir de sentir vergonha, culpa e responsabilidade pessoal sobre atrocidades históricas e opressões contínuas para uma análise crítica e um ativismo institucional e sistêmico em defesa de raça, cultura e etnia. Os aspectos mais preocupantes da diversidade - aqueles que são relacionados à raça - são frequentemente 
marginalizados ou saneados para que fiquem mais palatáveis para os alunos da maioria euro-americana. Uma porcentagem excessivamente alta da responsabilidade de lidar explicitamente com a diversidade étnica e racial nos cursos de Pedagogia recai ainda sobre os professores de cor; e são poucos os estudantes de cor matriculados nos cursos de Pedagogia em universidades e faculdades predominantemente brancas.

Os desafios e os objetivos desta nova era da diversidade cultural são muito extensos para esperar que apenas alguns membros do corpo docente, unidades programáticas e componentes curriculares os atendam. Todo o quadro e aspectos dos cursos de Pedagogia devem participar, mas não necessariamente do mesmo modo ou no mesmo nível. Princípios de uma reforma sistêmica, formação diferenciada e aprendizado holístico são aplicáveis tanto à pedagogia para a diversidade cultural quanto para a efetiva implementação da educação multicultural nas salas de aula do ensino fundamental e médio.

Até o momento, houve mais progresso em aumentar a consciência e a percepção de professores atuais e futuros sobre a diversidade cultural do que na mudança dos comportamentos de ensino. Isto é promissor e problemático. É promissor porque crenças e atitudes são fundamentos importantes para a ação. E é problemático porque a consciência frequentemente se torna um substituto da ação, em vez de um estímulo e um termômetro, como legitimamente deveria ser; frequentemente ela sinaliza o fim em vez do começo do processo de mudança.

As atitudes, crenças, experiências e autoconceitos que tanto alunos quanto professores trazem para o curso de Pedagogia, os predispõem a reagir à diversidade étnica, racial e cultural de maneiras específicas (BRAND; GLASSON, 2004; BROWN, 2004; COCHRAN-SMITH, 2004; STUART; THURLOW, 2000). Por exemplo, Walker-Dalhouse e Dalhouse (2006) descobriram que futuros professores euro-americanos acreditam que o baixo desempenho ou altos níveis de problemas disciplinares que os alunos afro-americanos têm na escola derivam de uma falta de disciplina em casa, negligência parental, baixo interesse, valorização e motivação para aprender. Nenhuma responsabilidade é atribuída ao sistema educacional ou social por esses problemas. Os participantes desse estudo 
também expressaram sentimentos de desconforto, ansiedade e falta de eficácia em ensinar alunos afro-americanos, concordando, desse modo, com indivíduos em outros estudos e com a minha própria experiência de ensino. Embora muitos desses futuros professores acreditem que alunos etnicamente diversos têm direito a oportunidades educacionais equitativas e reconheçam o racismo como um grande problema. Por causa desses tipos de incertezas e dilemas, Cochran-Smith (2000) aconselhou os formadores de professores a se empenhar em modelar exatamente os tipos de currículo e instrução sobre raça, etnia, cultura, privilégio e opressão, que eles esperam que os futuros professores usem nas salas de aula da Educação Básica.

Crenças profundamente enraizadas agem como filtros para as novas informações sobre e encontros com a diversidade étnica, racial e cultural e são altamente resistentes à mudança (PAJARES, 1992; STUART; THURLOW, 2000). Elas também influenciam fortemente o sentimento de eficácia em ensinar a, para e por meio da diversidade cultural. Brown (2004) apontou que a autoconcepção dos professores "direciona suas percepções e comportamentos em relação aos alunos e formam a base da sua habilidade de integrar princípios multiculturais no ambiente da sala de aula, no ensino e nas avaliações." Portanto, formadores de professores precisam considerar as autoconcepções de seus alunos "quando estiverem desenvolvendo estratégias de ensino para diminuir [...] a resistência a percepções multiculturais e para aumentar o nível de comprometimento com a igualdade e a justiça social" (p. 137).

Essas atitudes podem explicar porque a consciência das diferenças culturais parece ser o aspecto mais ameno e aceitável para muitos alunos de Pedagogia, de todos os conhecimentos e habilidades incluídos nas experiências de aprendizagem multicultural oferecidas a eles. Eles estão expostos a muita "consciência" da diversidade cultural nas outras partes da sociedade em que participam antes de iniciar o curso de Pedagogia, tais como a cultura popular, lazer, empreendimentos comerciais, mídia de massa, política e mudanças de população. Pode ser por isso que muitos alunos nas minhas turmas de Educação Multicultural expressam medo e ansiedade de se engajar na diversidade étnica e cultural, 
pessoal e profissionalmente, no ensino em sala de aula, e porque eles pressupõem que qualquer conversa sobre pessoas de cor será controversa e contenciosa. Eles vêm para o curso de Pedagogia com atitudes já estabelecidas: percebem as pessoas de cor como patológicas, perigosas e ameaçadoras, similares às crenças encontradas por Walker-Dalhouse e Dalhouse (2006); Brown (2004); Jennings (2007) e Trent et al. (2008). É extremamente difícil que as experiências limitadas de Educação Multicultural que eles recebem desalojem essas crenças, contraponhamse a uma vida inteira de socialização e as substituam com informações mais precisas e crenças mais construtivas sobre pessoas étnica, racial e culturalmente diversas. Contudo, a necessidade urge, porque atitudes e crenças regem os comportamentos educativos.

Os educadores continuam debatendo se as crenças ou os comportamentos deveriam ser o primeiro alvo de mudança na formação de professores para a diversidade cultural. Obviamente, os dois têm importância crucial, mas eu recomendo começar com as atitudes e as crenças. É inconcebível para mim que professores que tenham crenças negativas sobre alunos etnicamente diversos e suas heranças culturais, como recursos educacionais válidos e viáveis, possam se relacionar com eles positivamente em interações pessoais e educacionais. Essa incongruência pode ajudar a explicar porque muitas gerações de reformas que visavam aos alunos étnica e culturalmente diversos não tiveram impactos significativos e sustentáveis em seus rendimentos escolares. De todo modo, as prioridades estão claras, os futuros professores precisam confrontar suas atitudes e suas crenças, bem como desenvolver bases de conhecimentos dos conteúdos, habilidades pedagógicas e de relacionamento interpessoal para ensinar os currículos e alunos culturalmente diversos.

Em última análise, a questão principal não é se iniciamos a formação de professores para a diversidade cultural pelas crenças ou pelo comportamento. Essas escolhas podem refletir meras preferências pessoais, orientações ideológicas, políticas de disciplina e estilos pedagógicos de vários formadores de professores. A questão mais importante é reconhecer que examinar crenças e atitudes sobre a 
diversidade cultural e desenvolver conhecimentos cognitivos e habilidades pedagógicas são elementos essenciais da formação de professores. Esses aspectos são profundamente interligados, interativos e complementares. Um não pode ser completamente realizado sem lidar com o outro, tanto na preparação profissional de professores quanto na prática em sala de aula de professores e de formadores de professores. 


\section{Referências}

AYERS, W. In the country of the blind: telling our stories. In: SCHUBERT, W. H.; AYERS, W. C. (Eds.). Teacher lore: learning form our own experience. New York: Longman, 1992. p. 154-158.

AYERS, W. Teaching the personal and the political: essays on hope and justice. New York: Teachers College Press, 2004.

BANKS, J. A.; BANKS, C. A. M. (Eds.). Handbook of research on multicultural education. 2. ed. San Francisco: Jossey-Bass, 2004.

BANKS, J. A.; BANKS, C. A. M. (Eds.). Multicultural education: issues and perspectives. 6. ed. New York: Jonh Wiley, 2007.

BRAND, B. R.; GLASSON, G. E. Crossing cultural borders into science teaching: early life experiences, racial and ethnic identities, and beliefs about diversity. Journal of Research in Science Teaching, v. 41, n. 2, p. 119-141, 2004.

BROWN, E. The significance of race and social class for self-study and the professional knowledge base of teacher education. In: LOUGHRAN, J. J. et al. (Eds.). International handbook of self-study of teaching and teacher education practices. Boston: Klumer Academics, 2004. p. 517-574.

BROWN, E. L. The relationship of self-concept to changes in cultural diversity awareness: implications for urban teacher educators. Urban Education, v. 36, n. 2, p. 119-145, 2004.

CASE, K. A.; HEMMINGS, A. Distancing strategies: white women preservice teachers and antiracist curriculum. Urban Education, v. 40, n. 6, p. 606-626, 2005. 
COCHRAN-SMITH, M. Blind vision: unlearning reacism in teacher education. Harvad Educational Review, v. 70, n. 2, p. 157-190, 2000.

COCHRAN-SMITH, M. Walking the road: race, diversity, and social justice in teacher education. New York: Teachers College Press, 2000.

COCHRAN-SMITH, M.; DAVIS, D.; FRIES, K. Multicultural Teacher education: Research, practice, and policy. In: BANKS, J. A.; BANKS, C. A. (Eds.). Handbook of research on multicultural education. 2. ed. San Francisco: Jossey-Bass, 2004. p. 931-975.

CUBAN, L. A fundamental puzzle of school reform. Phi Delta Kappan, v. 69, n. 5, p. 341-334, 1988.

GAY, G. Culturally responsive teaching: theory research, \& practice. New York: Teachers College Press, 2000.

GOOD, T. L.; BROPHY, J. E. Looking in classrooms. 9. ed. Boston: Allyn \& Bacon, 2003.

GRANT, C. A.; ELSBREE, A. R.; FONDRI, S. A decade of research on the changing terrain in multicultural education research. In: BANKS, J. A.; BANKS, C. A. (Eds.). Handbook of research on multicultural education. 2. ed. San Francisco: Jossey-Bass, 2004. p. 184-207.

HOWARD, G. R. We can 't teach what we don't know: white teachers, multiracial schools. 2. ed. New York. Teachers College Press, 2006.

JENNINGS, T. Addressing diversity in U.S. teacher preparation programs: A survey of elementary and secondary programs, priorities, and challenges from across the U.S. of America. Teaching and Teacher Education, v. 23, n. 8, p. 1.258-1.271, 2007.

KING, J. E.; HOLLINS, E. R.; HAYMAN, W. C. (Eds.). Preparing 
teachers for cultural diversity. New York: Teachers College Press, 1997.

KNOPP, T. Y.; SMITH, R. L. A brief historical context for dispositions in teacher education. In: SMITH, R. L.; SKARBEK, D.; HURST, J. (Eds.). The passion teaching: dispositions in the schools. Lanham. MD: Scarecrow Education, 2005. p. 1-13.

KOZOL, J. The shame of the nation: the restoration of apartheid schooling in America. New York: Crown, 2005.

LARKIN, J. E.; SLEETER, C. E. (Eds.). Developing multicultural teacher education curricula. Albany: State University of New York Press, 1995.

LOUGHRAN, J. J. et al. (Eds). International handbook of self-study of teaching and teacher education practices. Boston: Kluwer Academics, 2004.

LOUGHRAN, J. J.; RUSSELL, T. L. (Eds.). Improving teacher education practices through self-study. New York: Roudedge/Falmer, 2002.

MEIER, D.; WOOD, D. (Eds.). Many children left behind: how the no child left behind act is damaging our children and our schools. Boston: Beacon Press, 2004.

MILNER, H. R. (Ed.). Diversity and education: teachers, teaching, and teacher education. Springfield, 11.: Charles C. Thomas, 2009.

NIETO, S. (Ed.). Why we teach. New York: Teachers College Press, 2005.

OAKES, J. Keeping track: how schools structure inequality. 2. ed. New Haven, CT: Yale University Press, 2005.

PAJARES, M. F. Teachers' beliefs and educational research: cleaning up a messy construct. Review of Educational Research, v. 62, n. 3, p. 307332, 1992. 
RATHS, J.; MCANINCH, A. C. (Eds.). Teacher beliefs and classroom performance: the impact of teacher education. Greenwich. CT: lnformation. Age Publishers, 2003.

SCHUBERT, W. H.; AYERS. W. C. (Eds.). Teacher lore: learning from our experience. New York: Longman, 1992.

SLEETER, C. E. Preparing teachers for culturally diverse schools: Research and the overwhelming presence of whiteness. Journal of Teacher Education, v. 52, n. 2, p. 94-106, 2001.

SMYLIE, M. A. Teacher learning in the work place: implications for school reform. In: GUSKEY, T. R.; HUBERMAN, M. (Eds.). Professional development in education: new paradigms and practices New York: Teachers College Press, 1995. p. 92-113.

STUART, C.; THURLOW, D. Making it their own: preservice teachers' experiences, beliefs, and classroom practices. Journal of Teacher Education, v. 51, n. 2, p. 113-121, 2000.

TRENT, S. C.; KEA, C. D.; OH, K. Preparing preservice educators for cultural diversity: how far have we come? Exceptional Children, v. 74, n. 3, p. 328-350, 2008.

VILLEGAS, A. M.; LUCAS, T. Preparing culturally responsive teachers: rethinking the curriculum. Journal of' Teacher Education, v. 53, n. 1, p. 20-32, 2002.

WALKER-DALHOUSE, D.; DALHOUSE, A. D. Investigating white preservice teachers' beliefs about teaching in culturally diverse classrooms. The Negro Educational Review, v. 57, n. 1-2, p. 69-84, 2006.

Recebido em 10/09/2014 Aprovado em 25/11/2014 